Article

\title{
The Effect of Ti-6Al-4V Alloy Surface Structure on the Adhesion and Morphology of Unidirectional Freeze-Coated Gelatin
}

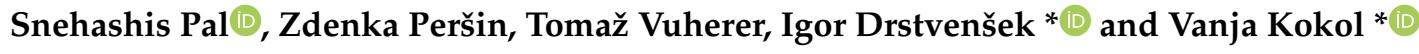 \\ Faculty of Mechanical Engineering, University of Maribor, Smetanova ul. 17, SI-2000 Maribor, Slovenia; \\ snehashiseu@gmail.com (S.P.); zdenka.persin@um.si (Z.P.); tomaz.vuherer@um.si (T.V.) \\ * Correspondence: igor.drstvensek@um.si (I.D.); vanja.kokol@um.si (V.K.); Tel.: +386-2-220-7593 (I.D.); \\ +386-2-220-7896 (V.K.)
}

Received: 2 April 2020; Accepted: 24 April 2020; Published: 28 April 2020

\begin{abstract}
The modification of a metal implant surface with a biomimetic coating of bone-like anisotropic and graded porosity structures to improve its biological anchorage with the surrounding bone tissue at implanting, is still a high challenge. In this paper, we present an innovative way of a gelatin (GEL) dip-coating on Ti-6Al-4V substrates of different square-net surface textures by the unidirectional deep-freezing process at simultaneous cross-linking using carbodiimide chemistry. Different concentrations of GEL solution were used to study the changes in morphology, density, and mechanical properties of the coatings. In addition, the surface free energy and polarity of Ti-6Al-4V substrate surfaces and GEL solutions have been evaluated to assess the wetting properties at the substrate interfaces, and to describe the adhesion of GEL macromolecules with their surfaces, being supported by mechanical pull-out testing. The results indicate that the coating's morphology depends primarily on the Ti-6Al-4V substrate's surface texture and second, on the concentration of GEL, which further influences their adhesion properties, orientation, morphological arrangement, as well as compression strength. The substrate with a $300 \times 300 \mu \mathrm{m}^{2}$ texture resulted in a highly adhered GEL coating with $\geq 80 \%$ porosity, interconnected and well-aligned pores of $75-200 \mu \mathrm{m}$, required to stimulate the bone ingrowth, mechanically and histologically.
\end{abstract}

Keywords: Ti-6Al-4V surface; gelatin; coating; morphology; mechanical properties; adhesion

\section{Introduction}

Modern rehabilitative implantology relies on titanium-based alloys that assure an implant's mechanical resistance to dynamic loads, with excellent corrosion resistance and a reasonable level of bioconductivity (osseointegration) and biocompatibility. The main drawback of titanium implants is related to their Young's modulus, that is usually much higher than cortical bone (110 vs. $20 \mathrm{GPa}$ ), their bioinertness, as well as anisotropic and hierarchical structure [1,2], which lowers the interaction with the host bone tissue [3]. If the implant does not get enough mechanical fixation, the loads cause relative micromovement between bone and implant, which leads to bone abrasion at the interaction surface, and further loss of mechanical strength and the implant's loosening. The marginal bone loss surrounding the implant retracts due to the formation of fibrous tissue, which results in a weaker bone formation and inflammation [4]. Since bone is a dynamic tissue, its density and mechanical properties are remodeled constantly according to its mechanical loadings. Thus, the stiffer metal implant carries the majority of applied loads, leaving the bone tissue effectively unstressed, which causes bone atrophy.

These issues have been addressed by the production of custom-made, porous titanium implants with a lower mechanical stiffness using an additive manufacturing technology (3D printing [5]) such as 
selective laser melting (SLM) [6]. By additional surface modification of these implants using chemical treatments [7], biomimetic hydroxyapatite [8], collagen $[4,9,10]$, or gelatin/GEL $[3,9,10]$ coatings, the bone ingrowth can be stimulated through relevant physicochemical, mechanical, and biological properties of the surface $[3,4,9]$. Several ways to modify the titanium alloy surface with a biopolymeric porous coating have also been introduced to mimic the texture/porosity of the bone, and to provide biological anchorage with the surrounding bone tissues [11,12], including, e.g., a chitosan-GEL coating applied by electrophoretic deposition [13] and nanohydroxyapatite/poly(epsilon-caprolactone) applied by electrospinning [14].

Besides, it is also well documented that the pore size of the implant's surface improves osteogenesis, while the degree of porosity with the interconnected porous structure leads to a tissue ingrowth $[15,16]$, vascularization, and nutrient supplementation [17,18]. Nouri et al. (2010) [11] proposed that a minimum $10 \mu \mathrm{m}$ pore size is required for bone ingrowth, considering the thickness of bone trabeculae and osteons cells. On the other hand, pore sizes in the range from 75 to $150 \mu \mathrm{m}$ [16] to $300 \mu \mathrm{m}$ [19] have been proposed, based on an in vivo study into canine femurs for a 4 to 22 week period and poly(propylene fumarate) scaffolds implanted into a subcritical size rabbit cranial defect [19]. Even the pores of around $600 \mu \mathrm{m}$ with $61 \%-65 \%$ porosity showed very high fixation ability, based on the in vivo investigation [20]. As the porosity of the human bone is about $70 \%-90 \%$, it is also suggested that a minimum $55 \%-60 \%$ [21,22], and optimally up to $90 \%$ [6,17], of porosity of the implant surface is required to stimulate the bone ingrowth, mechanically and histologically.

However, as the stability of the implants is strongly influenced by their macroscopic geometry rather than by the secondary geometry, which conditions interactions with the surrounding tissues and the subsequent phases of healing, it would, thus, be desirable to fabricate a biopolymeric coating with a biomimetic structure. Among various fabrication techniques, freeze casting has been shown to be one of the most promising techniques to produce such structures $[23,24]$ by controlling the anisotropic solidification of a solvent, typically water, as a template within a sol-gel solution, followed by its sublimation [25].

In this research, Ti-6Al-4V substrates with different surfaces of $\mu \mathrm{m}$-size square-net texture have been manufactured by SLM technology. They have been further dip coated with a biocompatible and extracellular matrix (ECM)-related biomimetic gelatin (GEL), a denatured product of collagen with well-accessible cell adhesion promoting Arg-Gly-Asp (RGD) active entities in its polymeric structure [3,26-29], by cooling the substrates with nitrogen passing through the conformal cooling channel beneath the surface. It has been expected that the textures of substrates influence the density and adhesion of GEL macromolecules to the surface of substrates, as well as their orientation and morphological arrangement (porosity size, shape, and gradient), during the cryogelation process according to our previous study [24], and, thus, we developed bone-like anisotropic and graded porosity coating structures that would stimulate the bone ingrowth, mechanically and histologically. We believe that such a coating could be applied ad-hoc to any metal-based device just before implanting, if it possesses suitable surface chemistry, also acting as a controllable drug-delivery system [24].

\section{Materials and Methods}

\subsection{Materials}

Ti Grade-23 alloy (Ti-6Al-4V ELI of 99.5\% purity), provided by Dentaurum (Ispringen, Germany) was used for the production of substrates by Selective Laser Melting (SLM) technology. The bulk material consists of fully dense spherical powder particles with granulation between 5 and $40 \mu \mathrm{m}$. Gelatin (GEL) from bovine skin type B powder, Tris(hydroxymethyl)aminomethane hydrochloride (Tris- $\mathrm{HCl}$, 99.9\% ultra-pure grade), 1-ethyl-3(3-dimethylaminopropyl)-1-ethylcarbodiimide hydrochloride (EDC), $\mathrm{N}-\mathrm{Hydroxysuccinimide} \mathrm{(NHS),} \mathrm{ethylene} \mathrm{glycol,} \mathrm{diiodomethane,} \mathrm{and} \mathrm{formamide} \mathrm{were} \mathrm{provided} \mathrm{from}$ Sigma-Aldrich (Steinheim, Germany) and used as received. 


\subsection{Methods}

\subsubsection{Modeling and Manufacturing of Ti-6Al-4V Substrates}

Four types of Ti-6Al-4V substrates were designed by CAD, and manufactured by selective laser melting (SLM) technology. The substrates were equipped with conformal cooling channels, in a spiral shape, directly below the coating surface. A unique homogeneous reticulated texture was applied to each of the substrates' coating surfaces (Figure 1a). The nets were square in shape with dimensions of $900 \times 900 \mu \mathrm{m}^{2}$ (abbreviated as Sub-1), $600 \times 600 \mu \mathrm{m}^{2}$ (Sub-2), $300 \times 300 \mu \mathrm{m}^{2}$ (Sub-3), and with no net (Sub-4), respectively; the square-net type of structure was chosen according to the previous studies $[6,11,12,17,18,20-22,30]$, being reported that the higher surface area boosts the bone ingrowth. The volumetric dimensions of the substrates were $32 \times 32 \times 10 \mathrm{~mm}^{3}$. The upper side of the samples (Figure 1b) had one inlet and one outlet gate, which were connected to a spiral cooling channel with a diameter of $3 \mathrm{~mm}$, situated inside the substrate (Figure 1c). The substrates were manufactured in an argon atmosphere with $0.8 \%$ remaining oxygen level and temperature of $20^{\circ} \mathrm{C}$ in an mLAB SLM machine (Concept Laser, Lichtenfels, Germany). The SLM laser processing parameters were selected as per the previous research, where the laser power, scanning speed, and hatch spacing were $85 \mathrm{~W}, 700$ $\mathrm{mm} / \mathrm{s}$, and $77 \mu \mathrm{m}$, respectively, and the layer thickness was $25 \mu \mathrm{m}$ [31].
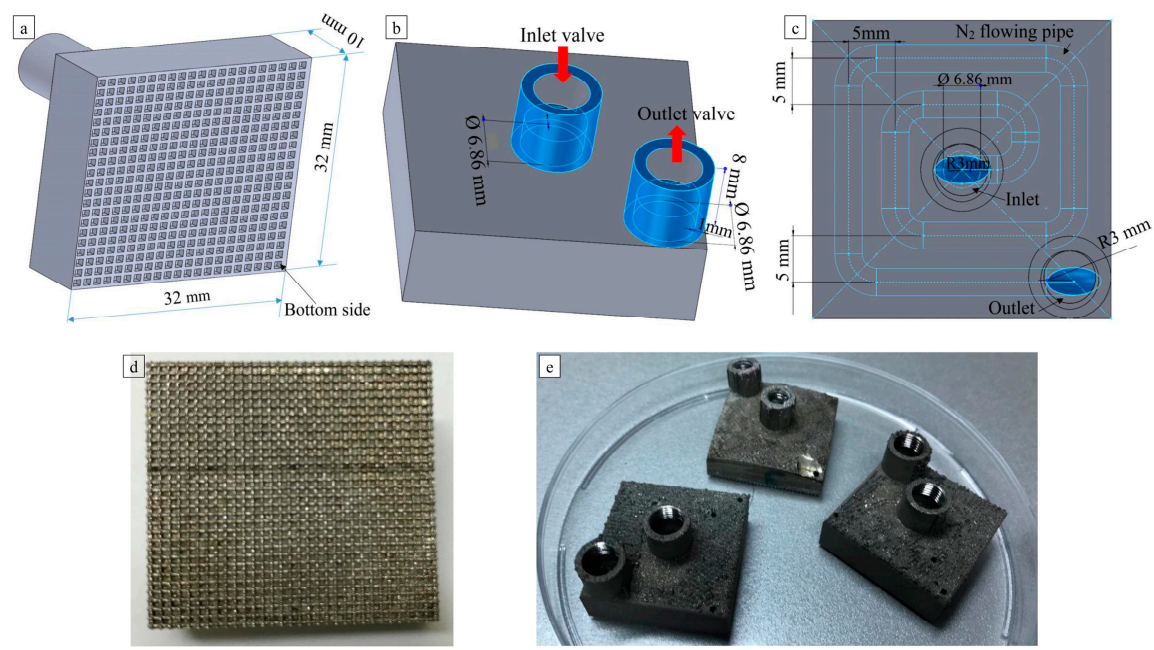

Figure 1. Experimental substrates: (a) 3D CAD model of a substrate showing a textured surface at the bottom side; (b) top side with an inlet and outlet for the nitrogen used as a coolant; (c) inner structure showing the conformal cooling channel connected to both inlet and outlet; (d) textured side of a Ti-6Al-4V substrate manufactured by selective laser melting (SLM); and (e) upper sides of three Ti-6Al-4V substrates manufactured by SLM.

\subsubsection{Performing of GEL Freeze-Coating on Ti-6Al-4V Substrate Surfaces}

$1 \%, 5 \%$, and $10 \%$ solutions of GEL in $10 \mathrm{mM}$ Tris- $\mathrm{HCl}$ buffer of $\mathrm{pH} 8.5$ were prepared under bland stirring at about $35^{\circ} \mathrm{C}$. The EDC at molar ratios of $2.5 / 1$ with respect to the number of GEL free amino groups, mixed with NHS in the fixed EDC/NHS molar ratio of 4/1, was added right before the incubation of the alloys, to perform GEL macromolecules' cross-linking in situ by carbodiimide chemistry [24]. In this reaction, the EDC reacts with the carboxyl groups of glutamic (Glu) or aspartic (Asp) acid residues in the GEL molecules to form an amine-reactive intermediate (o-acylisourea) that is stabilized by reaction with nonprotonated amino groups of other amino acid residues (such as lysine (Lys) and hydroxylysine (Hyl)), thus forming amide (peptide) bonds.

The textured surface of the Ti-6Al-4V substrates was immersed into a GEL solution $1 \mathrm{~mm}$ below the surface. The substrates were cooled down $\left(-5 \pm 2{ }^{\circ} \mathrm{C}\right)$ by the nitrogen cooling system (Figure 2a,b). The cooling gradient was controlled on-line by the temperature sensors attached to the experimental surface 
of the substrates, and the Supercool software. At the beginning of the experiment, the temperature of the GEL solution was $35 \pm 1{ }^{\circ} \mathrm{C}$. After the substrates were cooled down to the predefined temperature, the GEL solutions were left freezing for $36 \pm 1 \mathrm{~min}$ (Figure 2c), corresponding to the similar thickness of GEL coatings on the surface of the alloys (Figure 2d). The prepared GEL-coated substrates were lyophilized for $72 \mathrm{~h}$ at a temperature of about $-50{ }^{\circ} \mathrm{C}$ and pressure of $0.5 \mathrm{mmHg}$ using Mini Lyotrap Freeze Dryers provided by LTE Scientific (Oldham, UK), to sublime all ice crystals of water being generated during the freezing process. The coatings were cylindrical in shape, being 9-10 $\mathrm{mm}$ in diameter and 7-9 $\mathrm{mm}$ in height after lyophilization (in a dry state), but being reduced to about a few $100 \mu \mathrm{m}$ when being compressed in the wet stage.
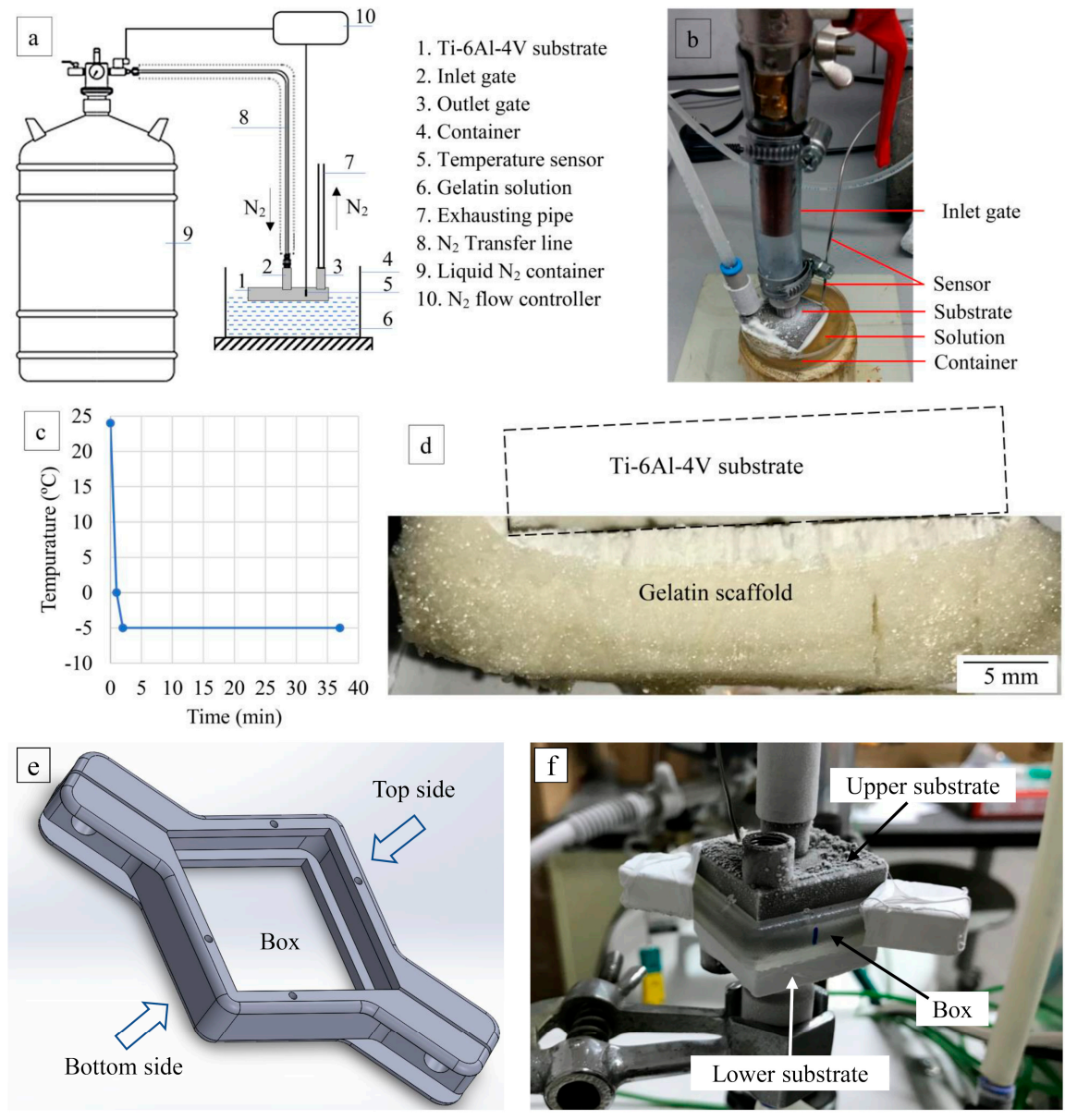

Figure 2. (a) Schematic and (b) snapshot presentation of a gelatin (GEL) coating on Ti-6Al-4V substrate by a cooling system; (c) kinetic and time of GEL cooling during coating on the substrate being cooled at $-5 \pm 2{ }^{\circ} \mathrm{C}$ for $36 \pm 1 \mathrm{~min}$, respectively; (d) an illustrated example of the frozen GEL on the substrate; (e) the box for the use of GEL freezing in-between two substrates; and (f) freezing the GEL in-between two substrates for the use of pull-out testing.

\subsubsection{Measuring of Pore Size and Pore-Size Distribution of the GEL Coating}

The mercury intrusion porosimetry (MIP) method using the Pascal 140 computer-aided porosimeter in the pressure range from 0.1 to $400 \mathrm{kPa}$ was used for measuring the pore size and pore-size distribution of the middle parts of the frozen coatings, without affecting the morphology of the samples.

\subsubsection{Scanning Electron Microscopy (SEM) analysis of GEL coatings}

SEM imaging of the cross-sections of GEL coatings (razor blade-cut) was performed to trace the effects of different substrate texture on coating morphology. The coatings were removed from the 
alloy surface, mounted using double-sided carbon tape, sputter-coated with gold, and examined with the microscopy equipment (high-vacuum Sirion NC 400 and Zeiss Ultra Plus) using backscattered (BSE) modes at different magnifications. The average pore sizes of the coatings were evaluated from 10 random pores by geometrical measurements (widths and heights) on scanning electron micrographs.

\subsubsection{Determination of Surface Tension (ST) Properties of Test Liquids and GEL Solutions}

The ST properties of selected test liquids (i.e., Milli-Q water/W, ethylene glycol/EG, diiodomethane/DI, and formamide/F) and their polar $\left(\gamma_{1}^{\mathrm{P}}\right)$ and dispersive $\left(\gamma_{1}^{\mathrm{D}}\right)$ components were determined using the pendant drop method on a goniometer (OCA 35 model, DataPhysics, Filderstadt, Germany). The Wilhelmy plate method (DIN 53 914) was used on the Processor Tensiometer K12 (Krüss $\mathrm{GmbH}$, Hamburg, Germany) to measure the ST of differently concentrated GEL solutions (GEL1: 1\%, GEL5: $5 \%$, and GEL10: $10 \%)$ at $35 \pm 1{ }^{\circ} \mathrm{C}$. The polar $\left(\gamma_{1}^{\mathrm{P}}\right)$ and dispersive $\left(\gamma_{1}^{\mathrm{D}}\right)$ components of the GEL' ST were evaluated upon contact angle (CA) measurements using a standard poly(tetrafluoroethylene) (PTFE) plate.

\subsubsection{Measurement of Contact Angle (CA) of Test Liquids and GEL Solutions on Ti-6Al-4V Substrates}

In order to evaluate the surface energy of Ti-6Al-4V substrates, the CA measurement of selected test liquids (described under 2.2.5) on substrates was performed using a goniometer (OCA 35 model, DataPhysics). In addition, the CA was determined between the substrates and GEL solutions (1\%, $5 \%$, and $10 \%$ ). The measurements with test liquids were performed at $20 \pm 2{ }^{\circ} \mathrm{C}$, while the measurements of the GEL solutions were carried out at $35 \pm 1{ }^{\circ} \mathrm{C}$. The substrates were placed on the table under a stainless-steel needle $(0.16 \mathrm{~mm}$ inner diameter). The test liquid/solution was placed in a $500 \mu \mathrm{L}$ glass tube (DataPhysics) and pushed automatically through a PTFE plastic tube (DataPhysics) to form a droplet. The sessile drop method was used for performing the receding and advancing CA measurements. The droplet was dispensed on the substrate in the volume of $3 \mu \mathrm{L}$, thus forming the advancing CA. Sucking the volume of $1 \mu \mathrm{L}$ back into the syringe, the residue volume-drop formed the receding CA. The droplet equilibrated before CA measurement was taken. The mean CA of each drop was measured 10 times in rapid succession and averaged to produce a single data point. This procedure was repeated at least 10 times, each time on a different position of the substrates' experimental surface, providing 100 data points on each sample. The average values of 10 independent measurements, including standard deviation (SD), are reported for each measurement.

After a series of measurements with the selected test liquid, the substrates were rinsed for $15 \mathrm{~min}$ in $100 \%$ ethanol (when using EG as a test liquid), or in 100\% acetone (when using DI), or in 100\% diethyl ether (when using F). After a series of measurements using the GEL solution, the samples were first rinsed in hot water $\left(T \geq 40^{\circ} \mathrm{C}\right)$ and then in ethanol $(100 \%)$. After the cleaning procedure, the samples were dried for $2 \mathrm{~h}$ at $40^{\circ} \mathrm{C}$.

\subsubsection{Determination of Surface Polarities and Free Energy of Immersional Wetting}

The measured characteristics of the materials involved at interfaces, i.e., ST, SFE, and their polar $\left(\gamma_{\mathrm{s}}^{\mathrm{p}}\right)$ and dispersive $\left(\gamma_{\mathrm{s}}^{\mathrm{D}}\right)$ components, were used to evaluate the percentage of surface polarities, by Equations (1) and (2) [32]:

$$
\begin{gathered}
\% \text { liquid surface polarity }=\frac{\gamma_{1}^{\mathrm{P}}}{\gamma_{1}} \cdot 100(\%) \\
\% \text { solid surface polarity }=\frac{\gamma_{\mathrm{s}}^{\mathrm{P}}}{\gamma_{\mathrm{s}}} \cdot 100(\%)
\end{gathered}
$$

The obtained values were used further to calculate the free energy of immersional wetting $\left(\Delta G_{i}\right)$ for the solid surface being wetted by liquid, using Equation (3):

$$
\Delta G_{i}=\gamma_{1}-2 \cdot \sqrt{\gamma_{\mathrm{s}}^{\mathrm{d}} \gamma_{1}^{\mathrm{d}}}+\sqrt{\gamma_{\mathrm{s}}^{\mathrm{p}} \gamma_{1}^{\mathrm{p}}}
$$


where $\gamma_{1}^{\mathrm{P}}$ is the polar component, $\gamma_{1}^{\mathrm{D}}$ is the dispersive component of the liquid's surface tension, and $\gamma_{1}$ is the surface tension of the liquid. For the solid, $\gamma_{\mathrm{s}}^{\mathrm{p}}$ is the polar, $\gamma_{\mathrm{s}}^{\mathrm{D}}$ is the dispersive component of the solid sample surface energy, and $\gamma_{\mathrm{s}}$ is the SFE of the solid.

\subsubsection{Compression Testing of GEL Coatings}

Compressive strength (yield strength) and Young's modulus of the GEL coatings in a dry and wet states were measured by compression testing using a Tensile Testing Unit (TTU) 2002 of SMITWELD 1405 testing machine (Lincoln Smitweld, Nijmegen, The Netherlands); to evaluate the coating's mechanical properties in a wet state, samples were immersed in phosphate buffer saline (PBS) for $2 \mathrm{~h}$ (when the adsorption equilibrium was definitely achieved) at $37^{\circ} \mathrm{C}$ before testing. Six samples, being extracted from each coating, were tested for each testing condition. The force was applied parallel to the direction of the frozen coating. The speed of the crosshead was set at $0.6 \mathrm{~mm} / \mathrm{min}$, and the compressive load was applied until the sample had been compressed to about $20 \%$ of its original length. The compressive strength and Young's modulus were measured by the maximum point and the slope of the initial linear portion of the stress-strain curve, respectively.

\subsubsection{Pull-Out Mechanical Testing}

A plastic box was designed using $\mathrm{CAD}$, and manufactured using 3D printing for the use of freezing the GEL solutions in-between two substrates (Figure 2e). The box has two open sides, the bottom side and top side. Two similar substrates had been placed face-to-face, inserted from both sides, and a $4 \mathrm{~mm}$ gap kept between their faces. The whole system, along with the box and two substrates, was placed in the freezing system. Both substrates were cooled down simultaneously by passing nitrogen through them. The same freezing method was applied as explained earlier. Thereafter, the box and the substrates together were put into the freeze dryer, and the same freeze-drying process was followed as mentioned earlier. After freeze-drying, the box and substrates were put into the pull-out system together, where the lower substrate was grounded, and the upper substrate was moved upwards at $0.6 \mathrm{~mm} / \mathrm{min}$. The pull-out load was applied until the complete separation of the substrates at the GEL scaffold region was obtained. The data were collected using a computer-controlled data acquisition system.

\section{Results and Discussion}

\subsection{The Influence of GEL Concentration and Ti-6Al-4V Substrate's Surface Texture on Coating Morphology}

The controlling of the GEL cryogelation process on Ti-6Al-4V substrates (its onset temperature, kinetic, and duration) is substantially important for the generation of an optimal porosity (pore size, structure, and gradient). The process is in a function of water crystallization growth and structuring around differently conformed GEL macromolecules (being influenced by their random coil vs. triple helix structure, influencing their physical aggregation), which become smaller and more ordered as the temperature decreases $[33,34]$. The temperature and time-extension intervals at which the onset of GEL gelation occurs were extracted from preliminary experiments (data not presented) by a set of sensors being located at the surface of the Ti-6Al-4V substrate as well as dipped in the GEL solution. However, as the inlet and outlet of the nitrogen coolant were at the center and corner of the substrate, respectively, the temperature of the substrates rose from the center to the corner points. This influenced the freezing speed, and hence, the crystal growth rates (Figure 2d). According to the GEL cooling kinetic, given a microstructure porosity on the outer (air-exposed) side of the coat, and processability of the device at the water-freezing temperatures, the cryogelation process was being thus performed at $-5 \pm 2{ }^{\circ} \mathrm{C}$ for $36 \pm 1 \mathrm{~min}$ (Figure 2c). After the lyophilization (in a dry state), the thickness of such a coating was about 9 to $7 \mathrm{~mm}$ from the center point to remote points, respectively, in all samples. This enabled us to understand the phenomena of morphological structuring of such a coating using different freezing kinetics and, above all, to emphasize the findings of the porosity inside the first 
millimeters of the whole coating thickness, which is the most relevant for the orthopedic application, as it can fit into the so-called trabecular surface of the implant, e.g., the surface that mimics the trabecular bone being composed of generated surface pores of specific geometry having sizes between 0.5 and 1.0 $\mathrm{mm}$. Our implants are all equipped with this kind of surface structure and coatings with appropriate morphology, while the thickness of generated coatings is reduced to about few $100 \mu \mathrm{m}$ when being compressed in a wet stage.

Figure 3 shows the SEM images of GEL coating cross-sections obtained from the center point of the coat on Ti-6Al-4V substrates with different textures using different concentrations of GEL solutions $(1 \%, 5 \%$, and $10 \%)$. Two types of images were inserted for each coating, the first one representing the cross-section of almost the entire coating along the freezing direction and the second one illustrating two particular points of the previous image, one near (upper point) and one away (lower point) from the substrate. Precisely, the chosen points were located at $100 \mu \mathrm{m}$ below the substrate and $100 \mu \mathrm{m}$ above the end of the GEL solution.

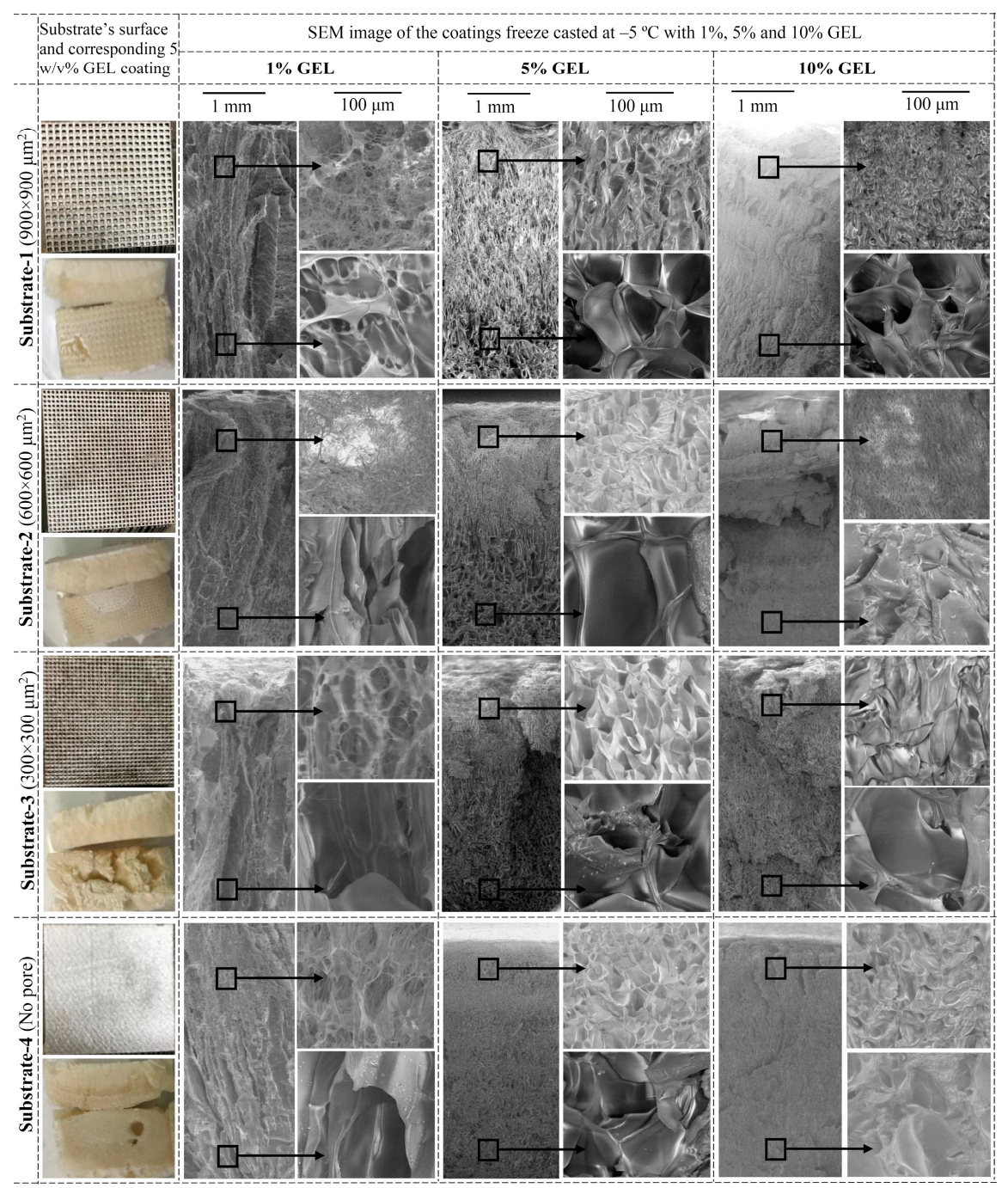

Figure 3. Photographs of different Ti-6Al-4V substrate textures and their $5 \%$ coatings, and SEM images of cross-sections of coatings fabricated on different substrates with $1 \%, 5 \%$, and $10 \%$ of GEL solutions.

The images show clearly the effect of both different concentrations of GEL solutions, as well as the texture of the substrates, on gradient structure and pore sizes within the coatings. The coatings displayed a gradient porous structure with lamella-type pores running along the freezing direction. This is most evident for coating performed with less concentrated GEL solutions (1\% and 5\%), which 
displays anisotropic pores clearly, aligned with the freezing direction. As expected for unidirectional freeze coating, the lower substrate's temperature, and thus, faster freezing velocity of the water, resulted in smaller pore sizes. A generally smaller porosity was thus observed close to the substrate, and it increased gradually within the coating towards the GEL solution-exposed side. During crystallization, heat is released that increases the temperature of the water back to its melting point, which results in a mixture of ice and water. Due to rapid cooling of the neighboring zone of the substrates, the heat of crystallization converts to the substrate, preventing large ice crystal formation. The heat transfer rate changes with the distance from the substrate during the freezing process of the GEL solution. Therefore, the pore sizes and inner structure of the GEL coating have been growing with the distance from the substrate's surface as the result of the reduced cooling rate. The coatings were also getting denser by lowering the substrates reticulated texture (from Sub-1 to Sub-4). The phenomenon is best expressed at $5 \%$ GEL coating, which may be the result of the most favorable wetting properties of this GEL solution with the substrate surfaces. Such lamellar pore structures are also well connected, which may have an influence on the coating mechanical properties, i.e., increased strength and stiffness.

As can be seen from the surfaces of the coatings close to the GEL solution-exposed parts (the side that would interact with the bone tissue), the pores are also more honeycomb-like and more open than plate-like structures in the case of coatings performed with less concentrated GEL solutions (1 and 5\%), while they have more dense and round-shape organized structure with much thicker walls in the case of coating prepared with $10 \%$ of GEL.

It was also observed that the pore size near the substrate was smaller, and grew towards the GEL solution-exposed surface (Table 1). The pore sizes near the substrate are generally in the range from 5 to $50 \mu \mathrm{m}$, whereas near the GEL solution-exposed side, they rise up to the range from 50 to $180 \mu \mathrm{m}$, depending highly on the concentration of GEL solution. The coatings with open porosity and more than $100 \mu \mathrm{m}$ pores have been reported to promote bone tissue ingrowth $[35,36]$. Thus, some coatings produced here (i.e., by 5\% GEL on Sub- 1 and Sub-2, as well as by $5 \%$ and $10 \%$ GEL on Sub-3) have suitable dimensions and morphological structure to be used as the outer layers of implants interacting with the bone. Furthermore, using the proposed method, their characteristics can be tuned further to reach the desired structure dimensions. It is shown that pore size can be modulated primarily by the substrates' texture (i.e., the larger the net, the larger the pores), while GEL concentration influences primarily the pore wall thickness and its shape, being also highly important for cells' permeation, attachment, and differentiation [20].

Table 1. Pore sizes of the coatings evaluated within $1 \mathrm{~mm}$ from the (A) Ti-6Al-4V substrates and (B) gelatin (GEL) solution-exposed side, by geometrical measurements (widths and heights) of at least 10 pores on scanning electron micrographs.

\begin{tabular}{ccccc}
\hline \multirow{2}{*}{ Substrate } & \multirow{2}{*}{ Place of Coating } & \multicolumn{3}{c}{ Range of Pore Size $(\boldsymbol{\mu m})$} \\
\cline { 3 - 5 } & & $\mathbf{1 \%}$ GEL & $\mathbf{5 \%}$ GEL & $\mathbf{1 0 \%}$ GEL \\
\hline \multirow{2}{*}{ Sub-1 } & A & $20-45$ & $25-40$ & $10-20$ \\
& B & $100-140$ & $75-100$ & $75-100$ \\
\hline \multirow{2}{*}{ Sub-2 } & A & $10-20$ & $20-30$ & $5-10$ \\
& B & $75-125$ & $75-100$ & $50-60$ \\
\hline \multirow{2}{*}{ Sub-3 } & A & $25-50$ & $30-40$ & $20-50$ \\
& B & $110-160$ & $70-90$ & $75-100$ \\
\hline \multirow{2}{*}{ Sub-4 } & A & $15-30$ & $20-30$ & $20-30$ \\
& B & $130-180$ & $60-80$ & $50-60$ \\
\hline
\end{tabular}

The total porosity and pore size distributions of the coatings performed with 5\% GEL solution on all Ti-6Al-4V substrate surfaces were, thus, also evaluated by the Mercury Intrusion Porosimetry (MIP) method. The results of the analysis, presented in Figure 4, indicate that Sub-1 and Sub-2 produced much higher void pore volumes with the average pore size of about 55 and $71 \mu \mathrm{m}$, respectively, and 
total porosity of about $90 \%$ compared to Sub-3 and Sub- 4 with about $17 \mu \mathrm{m}$ average pore sizes. It was observed that most of the pore sizes in coatings on Sub-2 measured between 36 and $85 \mu \mathrm{m}$, while they were between 20 and $64 \mu \mathrm{m}$ for Sub-1 and Sub-3 and less than $27 \mu \mathrm{m}$ (until $11 \mu \mathrm{m}$ ) on Sub-4. On the other hand, however, in the case of Sub-4, very equally distributed pore size structure can be observed to be in the range between 11 and $113 \mu \mathrm{m}$. Anyway, all the substrates, except Sub-3, produced a scanty number of large-sized pores with a diameter of 85-113 $\mu \mathrm{m}$, being volumetrically the highest (and located mainly on the coating outer side, as already ascertained by analysis of pore sizes from the SEM images (Table 1)) in the case of coating on Sub-2, and thus, the most appropriate for the bone ingrowth $[37,38]$. The porosity was also above $80 \%$ and pores were interconnected (as also seen from the SEM images (Figure 3)), with sufficient void space, which may enhance new bone and capillaries' formation $[16,20,22]$.

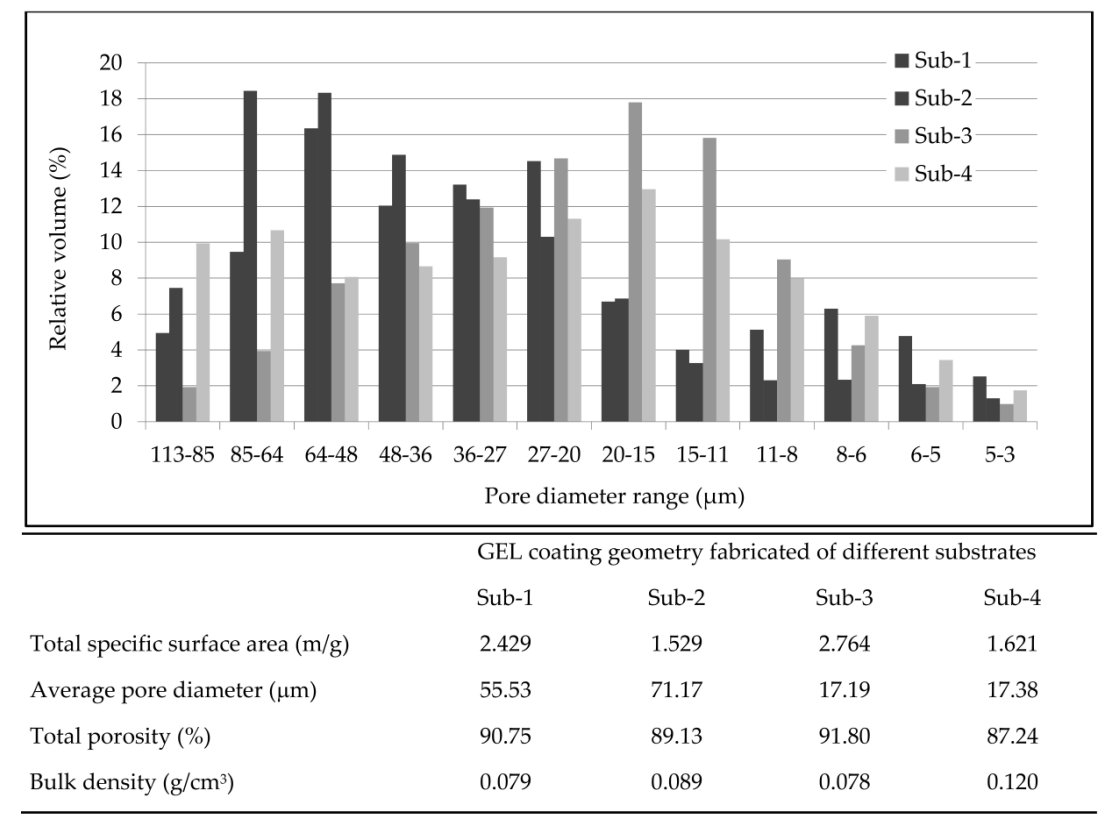

(a)

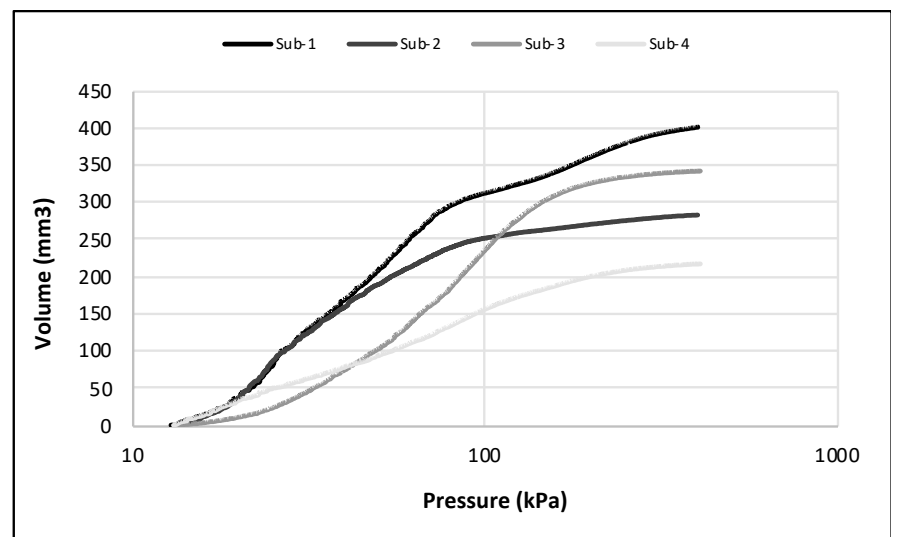

(b)

Figure 4. (a) Mercury porosimetry data with corresponding (b) Mercury Intrusion Porosimetry (MIP) curves of coatings performed with $5 \%$ of GEL solution on differently surface-textured Ti-6Al-4V substrates.

\subsection{The Adhesion of GEL Coatings on Different Ti-6Al-4V Substrates}

Surface properties, like the surface topography and wettability of solid materials, influence the adhesion and deposition/spreading of biological molecules [39,40]. To understand and predict the interactions between differently surface-textured Ti-6Al-4V substrates and GEL macromolecules better, 
as well as their spreading/orientation at the start of the coating, the surface free energy (SFE), polarities, and free energy of immersion wetting $\left(\Delta G_{i}\right)$ were evaluated by measuring the surface tension (ST) properties of GEL solutions as well as contact angle (CA) properties of substrate surfaces (the latter presented and discussed in the Supplement document) using selected test liquids with different polarities (i.e., Milli-Q water/W, ethylene glycol/EG, diiodomethane/DI, and formamide/F) and GEL solutions of different concentrations $(1 \%, 5 \%$, and $10 \%)$.

The SFE of the substrates were calculated by using three different calculation models to get a more reliable evaluation [41-44] of the interactions between the substrate surfaces and GEL solutions: A two-component model by Owens-Wendt-Rabel-Kaelble (OW) [44], the extended Fowkes (EF) theory [45], and a three-component model proposed by van Oss, Chaudhury, and Good (VO) [46]. In order to highlight the changes resulting from the different surface structure, and to facilitate comparison between the results of different models, the histogram for the total SFE was divided into polar $\left(\gamma_{\mathrm{s}}^{\mathrm{p}}\right)$ and dispersive $\left(\gamma_{\mathrm{s}}^{\mathrm{D}}\right)$ components (Figure 5).

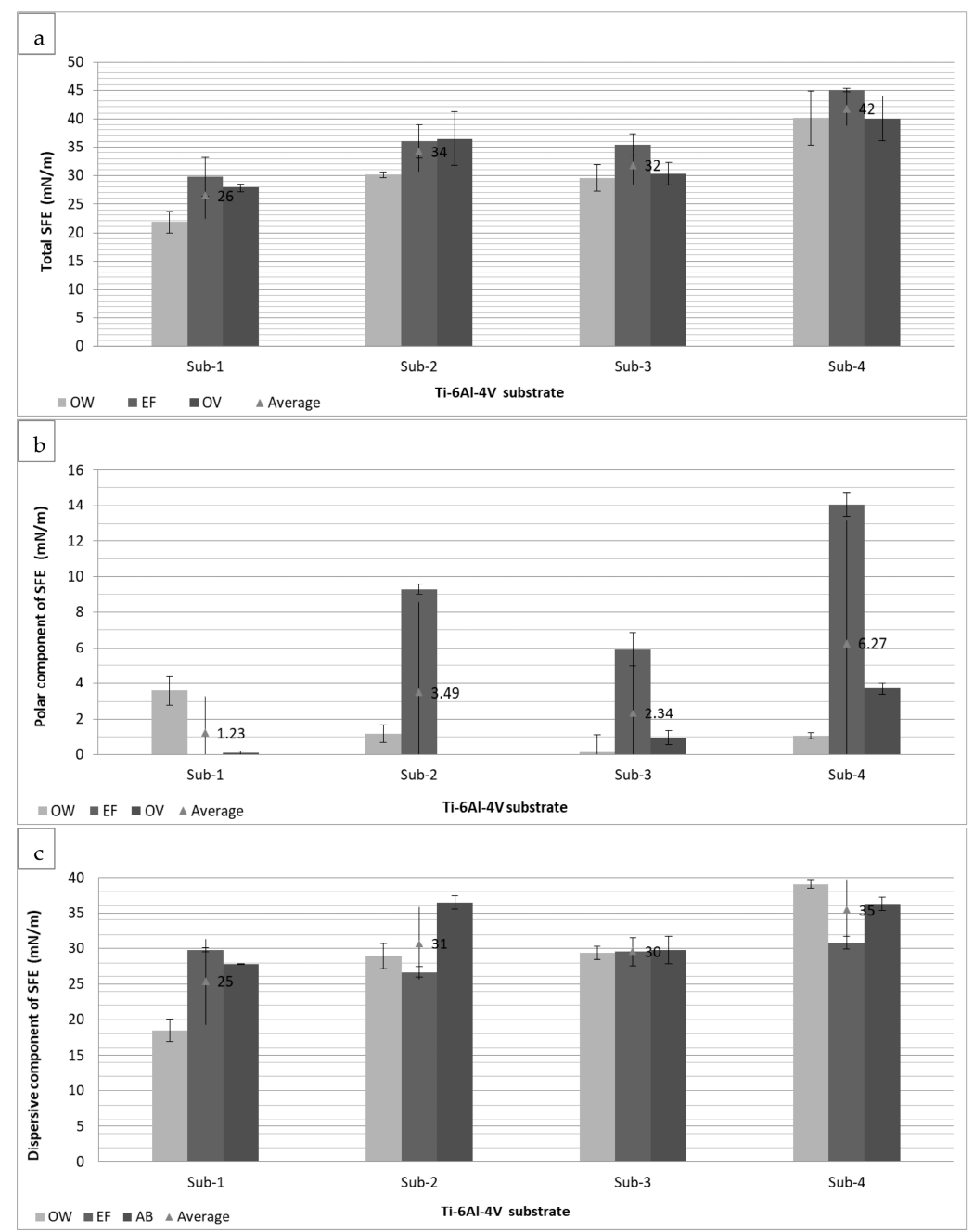

Figure 5. Total surface energy (SFE) (a) and polar (b) and dispersive (c) components of SFE of Ti-6Al-4V substrates calculated using different models (i.e., OW-Owens-Wendt-Rabel- Kaelble; EF-extended Fowkes; and VO—van Oss, Chaudhury, and Good); the average values of results obtained from different models used are noted as bullet points.

The average values of total SFE (Figure 5a), as obtained by different approaches, indicate the highest value $(42 \mathrm{mN} / \mathrm{m})$ for Sub-4 with the largest net texture $\left(900 \times 900 \mathrm{~cm}^{2}\right)$, and the lowest $(26 \mathrm{mN} / \mathrm{m})$ for the smooth Sub-1 surface, while Sub-2 and Sub-3 responded with values of 34 and $32 \mathrm{mN} / \mathrm{m}$, 
respectively. The same trend was observed with the dispersive (Figure $5 b$ ) and polar components (Figure 5c) of SFE, which varied between 2-7 and 4-6 mN/m, respectively, depending on the used calculation model. However, the calculated polar values were generally much lower compared to dispersive components, contributing $0.3 \%$ (Sub-1), $0.6 \%$ (Sub-3), 1\% (Sub-2), and 2.5\% (Sub-4) of the total amount of SFE.

Considering the different calculation models, the highest value of total SFE at all samples was calculated using the EF approach and the lowest by OW. The EF theory [45] describes dispersive components (London interactions arising from electron dipole fluctuations), polar components (van der Waals interactions), and the hydrogen bonding part. However, by using this approach, it was possible to calculate the hydrogen component only for Sub-4, being $0.1 \mathrm{mN} / \mathrm{m}$. On the other hand, the VO theory [46], which enables defining interactions resulting from hydrogen bonding (i.e., acidic $\left(\gamma_{s}^{+}\right)$and basic part $\left(\gamma_{\mathrm{s}}^{-}\right)$of the polar components), evidenced the presence of the basic part only for Sub-3 and Sub-4, with values of 0.48 and $3.7 \mathrm{mN} / \mathrm{m}$, respectively, indicating the presence of oxygen-containing groups. In addition, according to the-[47], SFE is the sum of apolar Lifshitz van der Waals component $\left(\gamma_{\mathrm{s}}^{\mathrm{LW}}\right)$ and polar Lewis acid base component composed of electron donor $\left(\gamma_{\mathrm{s}}^{-}\right)$and electron acceptor $\left(\gamma_{\mathrm{s}}^{+}\right)$, the Sub-4 indicated that its $\left(\gamma_{\mathrm{s}}^{-}\right)$component contributed $3.7 \mathrm{mN} / \mathrm{m}$ in comparison to $\left(\gamma_{\mathrm{s}}^{+}\right)$to the overall SFE. This indicated the more basic character of the Sub-4 surface, which may be the reason for its higher interactions (H-bonding) with water-based liquids. In general, substrates possess relatively low values of overall SFEs $(<50 \mathrm{mN} / \mathrm{m})$ and very low polar components, which indicate higher chances for biomolecules' proliferation $[48,49]$.

Since the dispersive components of SFE dominate in all substrates (Figure 5) and the polar components of ST dominate in GEL water solutions (Table S1 in the Supplement Materials), the substrates are willing to interact with the nonpolar/noncharged parts of the GEL macromolecules. On the other hand, the 15\%-25\% lower CA values (Table S3 in the Supplement Materials) obtained with $5 \%$ GEL compared to $1 \%$ GEL, could be explained by the changing of GEL supramolecular helix vs. coil structures to more ordered triple-helical segments at $5 \%$ of GEL [34]. This may lower its ST properties and, thus, higher interactions with the substrate surface, due to higher dispersive (nonpolar) interactions, which are dominating when taking into account the spreading of this GEL solution on the alloy surface. On the contrary, 1\% GEL solution contains highly extended and less ordered GEL macromolecules. Among substrates, the lowest CA was obtained with 5\% GEL on Sub-4, indicating the highest nonpolar interactions between the GEL macromolecules and smooth substrate with no texture, thus enabling the highest spreadability of GEL on such a surface. On the other hand, about $10 \%$ higher CA was obtained on Sub-1 with the largest micronet texture, followed by substrates 2 and 3 .

The solid and liquid polarities, along with the free energy of immersion wetting $\left(\Delta G_{i}\right)$, were calculated using the measured values for test liquids (i.e., STs and their polar and dispersive components collected in Table S1 of the Supplement document and average calculated values of total SFE and their dispersive and polar components by substrates, presented in Figure 5). According to the results listed in Table 2, and the fact that only a negative value of $\Delta G_{i}\left(\Delta G_{i}<0\right)$ means that the wetting is thermodynamically favorable, only the Sub-1 shows no affection to be wetted with water. Sub-1 also showed lower negative values of $\Delta G_{i}$ (between -6.24 and -20.47) irrespective of other used test liquids and GEL solutions, compared to other substrates $\left(\Delta G_{i}\right.$ was between -2.75 and -38.57$)$. Thus, Sub- 1 shows greater potential to be wetted by any GEL solution (irrespective of its concentration, $\Delta G_{i}=$ -17.87 to -19.37$)$ compared to other test liquids $\left(\Delta G_{i}=-6.24\right.$ to -20.47$)$. On the other hand, Sub-4 showed the highest values of $\Delta G_{i}$ with all test liquids $\left(\Delta G_{i}=-21.37\right.$ to -35.7$)$ and the most favorable wetting $\left(\Delta G_{i}=-39.05\right)$ with $5 \%$ GEL, followed by Sub-2 and Sub-3. In the case of polarities, Sub-4 was three times and $60 \%$ more polar compared to Sub-1 and Sub-2, respectively, indicating that the possible wetting between Sub-4 and GEL solutions could be based upon their polarities. This can also be supported by the fact that substrates with low polarities (i.e., Subs-1, -2 , and -3) are favorable to be wetted by DI, known as a nonpolar liquid ( $0 \%$ polarity), while Sub- 4 possesses a noticeable enough polarity for favorable wetting with EG, which is considered, also besides water, as a polar 
liquid. In addition, GEL solutions, regardless of their concentrations, showed, besides DI, lower values of polarities compared to the test liquids. Among the GEL solutions, a smaller value of polarity by $5 \%$ GEL (32.98\%) compared to 1\% GEL (35.47\%) and 10\% GEL (35.4\%) could be explained by the relationships between their ST (Table S1) and density [50], being highly related to their concentration. According to the latter, the densities increased with increase GEL concentration, thus resulting in decreased ST, being also supported by Osgouci et al. [51]. In addition, a smaller part of the polar component compared to the dispersive part of ST was due to the changing of GEL supramolecular structure, i.e., conformation and intermolecular associations, being related to its protein-protein and protein-dissolvent interactions, respectively [52].

Table 2. Polarities (\%) of Ti-6Al-4V substrates, test liquids, and GEL solutions and free energy of immersional wetting $\left(\Delta G_{i}\right)$ between them.

\begin{tabular}{|c|c|c|c|c|c|c|c|}
\hline \multirow{3}{*}{$\begin{array}{c}\text { Sample (\% } \\
\text { Polarity) }\end{array}$} & \multicolumn{7}{|c|}{ Free Energy of Immersional Wetting $\left(\Delta G_{i}\right)$} \\
\hline & \multicolumn{4}{|c|}{ Test Liquids (\% Polarity) } & \multicolumn{3}{|c|}{ GEL Solutions (\% Polarity) } \\
\hline & $\begin{array}{c}W \\
(63.73 \%)\end{array}$ & $\begin{array}{c}\text { EG } \\
(44.65 \%)\end{array}$ & DI (0\%) & $F(50.68 \%)$ & $\begin{array}{c}\mathrm{G} 1 \\
(35.47 \%)\end{array}$ & $\begin{array}{c}\text { G5 } \\
(32.98 \%)\end{array}$ & $\begin{array}{c}\text { G10 } \\
(35.39 \%)\end{array}$ \\
\hline Sub-1 (4.31\%) & 7.80 & -12.91 & -20.47 & -6.24 & -17.87 & -19.37 & -19.05 \\
\hline Sub-2 $(8.82 \%)$ & -8.01 & -25.50 & -28.57 & -20.27 & -29.38 & -30.38 & -29.94 \\
\hline Sub-3 $(6.25 \%)$ & -2.75 & -21.64 & -27.28 & -15.85 & -26.0 & -27.18 & -16.66 \\
\hline Sub-4 (14.29\%) & -21.37 & -35.70 & -33.53 & -31.80 & -38.51 & -39.05 & -38.57 \\
\hline
\end{tabular}

The GEL solution, and water as a liquid medium for interaction, can, thus, participate as a source of acid (proton) or base (removing proton). In addition, as a polar solvent, it has large dipole moments, containing bonds between different electronegative atoms (i.e., oxygen and hydrogen). The protic solvents possess $\mathrm{O}-\mathrm{H}$ or $\mathrm{N}-\mathrm{H}$ bonds, which can participate in $\mathrm{H}$-bonding and serve as a source of protons $\left(\mathrm{H}^{+}\right)$, i.e., they are acids. Obviously, it can be suspected that the $5 \%$ GEL solution was organized macromolecularly in a way dominating with more alike electronegative atoms [53], which were more likely interacting with the basic character of Sub-4.

The pull-out mechanical testing (in dry conditions) of representative GEL-coated samples was performed in addition to evaluating the adhesion of the coating to differently surface structured Ti-6Al-4V substrates quantitatively. The GEL coatings were the strongest ( 87 and $120 \mathrm{~N} / \mathrm{mm}^{2}$ ) on Sub-3 with the finest surface texture $\left(300 \times 300 \mu \mathrm{m}^{2}\right.$ square-net; Figure 6$)$, which may be, based on the above presented and discussed results, related to both the relatively high nonpolar interaction of GEL macromolecules with such a surface, as well as the surface microtexture, resulting in a conformationally optimal loading and interactions. On the other hand, even the adhesion of $10 \mathrm{~N} / \mathrm{mm}^{2}$ for $10 \%$ GEL coatings on Sub-1 and Sub-2 may be suitable [54].

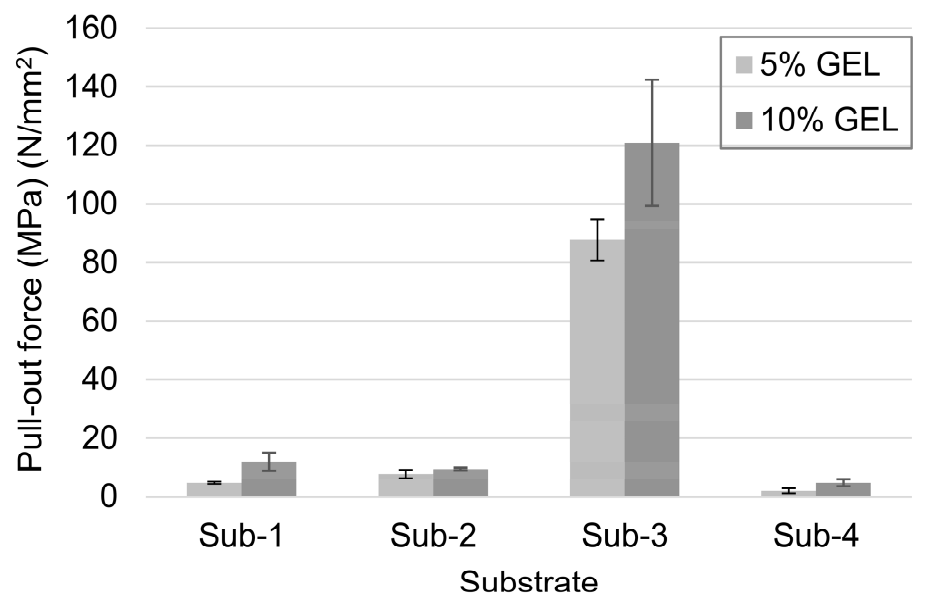

Figure 6. Applied forces to pullout the GEL coating from different substrates. 


\subsection{Compression Strength and Density Properties of GEL Coatings on Different Ti-6Al-4V Substrates}

One of the main challenges in improving a load-bearing implant is to preserve the mechanical strength while increasing the scaffold porosity [55] to favor cells' ingrowth and proliferation. On the other hand, such an implant would be pressed to the bone during implanting, and exposed to a physiological fluid inside the body, and, hence, it is also important to evaluate its mechanical strength in a wet state in vitro. Compressive properties of as prepared GEL coatings, as well as those immersed in PBS solution for $2 \mathrm{~h}$ at $37^{\circ} \mathrm{C}$ (which was more than enough time to achieve the equilibrium of adsorption) have thus been performed (Figure 7); here, it is also worth mentioning that none of the samples have changed, even after a few weeks of incubation in MQ water, which confirms their high stability. The compression tests were performed by the force applied along the freezing direction of differently concentrated (5\% and 10\%) GEL coatings on all types of substrates.

(a)

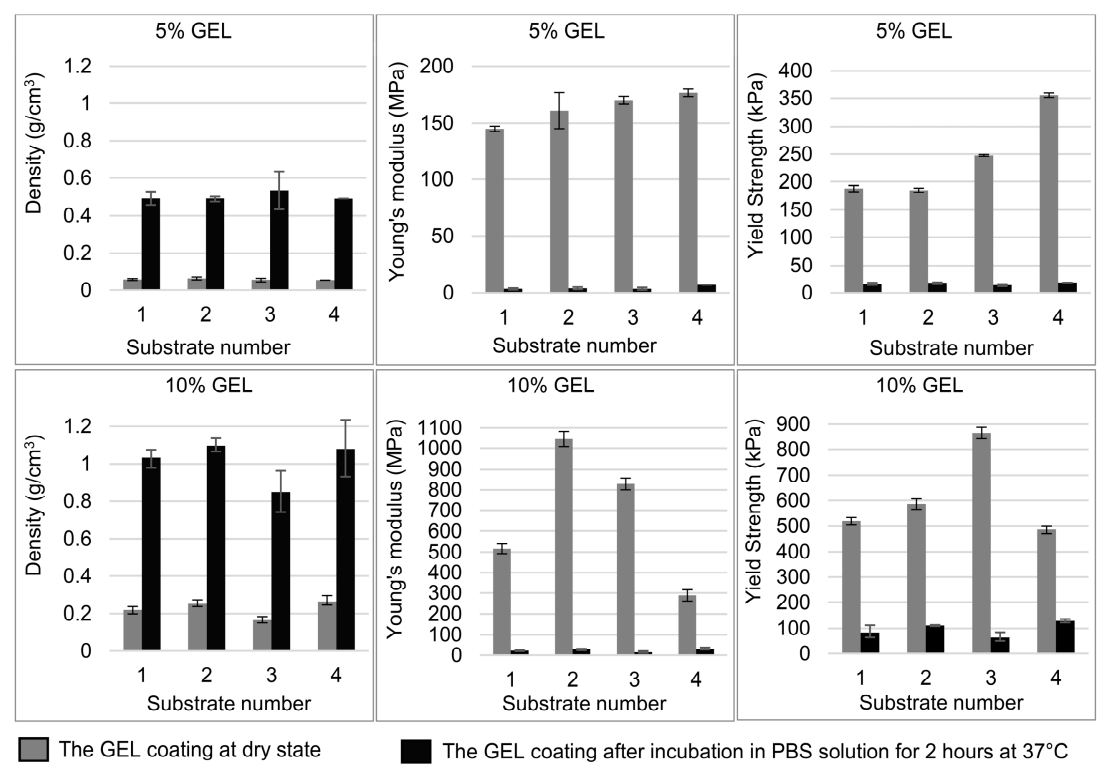

Figure 7. (a) Densities, (b) Young's modulus, and (c) yield strength of the coatings performed with $5 \%$ and $10 \%$ GEL solutions on differently surface-textured Ti-6Al-4V substrates, in a dry and a wet stage. The tests were performed by force applied along the freezing direction of the coating.

A significant difference can be observed between the coatings being measured in a dry or a wet stage, as well as the GEL concentrations used. The compression test results show clearly that the Young's modulus and yield strengths are decreased highly by the incubation in PBS. By applying the compression force on the dried samples, the pores are actually decreased in their volume and shape, which increases their strength, but that is not the case for the wetted samples, being much softer. A strength difference can also be observed between dry coatings prepared with solutions of different GEL concentrations. The Young's modulus and yield strengths of such coatings prepared with $10 \%$ GEL (288-1045 MPa and 485-865 kPa) are about two to four times higher than those prepared with 5\% GEL (145-176 MPa and 185-356 kPa) for each of the substrates. On the other hand, in the wet state condition, these values are four to six times higher for coatings prepared with 10\% GEL (14-31 MPa and 63-130 kPa) compared to those prepared with 5\% GEL (3-7 MPa and 14-19 kPa).

The surface texture of the Ti-6Al-4V substrate also has an important influence on the yield strengths of the coating for $10 \%$ of GEL solutions. In a dry state, it has been increased from about $519 \mathrm{kPa}$ at Sub-1 with the largest $\left(900 \times 900 \mu \mathrm{m}^{2}\right)$ reticulated texture to about $865 \mathrm{kPa}$ at Sub-3 (the texture of $300 \times 300 \mu^{2}$ ), while it decreased to about $485 \mathrm{kPa}$ at Sub-4 with a smooth (no net) surface. At the same time, Young's modulus increased from about $516 \mathrm{MPa}$ at Sub-1 (net of $900 \times 900 \mathrm{\mu m}^{2}$ ) to about $1045 \mathrm{MPa}$ at Sub-2 (net of $600 \times 600 \mu \mathrm{m}^{2}$ ) and $842 \mathrm{MPa}$ at Sub-3 (net of $300 \times 300 \mu \mathrm{m}^{2}$ ), while it again 
decreased to $288 \mathrm{MPa}$ at Sub-4 (with a smooth structure). The Sub-3 with the smallest porosity among all the coatings, having a net of $300 \times 300 \mu \mathrm{m}^{2}$ produced the highest strength and second-best Young's modulus of GEL coat in a dry state, at both GEL concentrations. The substrate surface structures have, however, no significant influence on the coating mechanical properties in the case of using 5\% GEL solutions, where the yield strengths are in the range of about 185-356 MPa. After incubation in PBS, the coating became softer and, thus, no significant difference can be observed in their mechanical strengths for the same GEL concentrated coatings. The yield strength of 10\% and 5\% GEL coatings became in the range of 63-130 and 14-18 kPa, respectively, whereas their Young's modulus was in the range of 14-31 and 3-7 MPa, respectively, which touched the limit of a human cancellous bone, being in the range of 2-12 MPa [55]. On the other hand, the average coating densities increased only about five times (in a dry state) and two times (in a wet state) by using 5\% GEL compared to the coatings performed with 10\% GEL. Nevertheless, the yield strength and Young's modulus can be modulated further by changing the concentration of the cross-linkers when performing the coating.

\section{Conclusions}

Biomimetic gelatin (GEL) coatings with different anisotropic graded porous structures and different compression mechanical properties were coated on Ti-6Al-4V substrate surfaces of different $\mu \mathrm{m}$-size square-net textures, manufactured by SLM technology. The coatings were applied by temperatureand time-controlled unidirectional freezing using different concentrations of GEL solutions and carbodiimide chemistry to cross-link it in situ, thus forming a soft and biodegradable thin-layer structure in vitro. It was ascertained that the texture of substrates' influences on the adhesion of GEL macromolecules to the surfaces, as well as their orientation, density, and morphological organization, being the strongest for the finest square-net surface texture $\left(300 \times 300 \mu \mathrm{m}^{2}\right)$ due to high nonpolar interactions. The coating morphology (porosity, pores' size, shape, and gradient) was additionally modulated by the cryogelation process, being in the range to allow bone ingrowth, while their pore wall thickness, which was growing with the increasing of GEL concentration, influenced the coating's compression strength and Young's modulus at similar density.

Although such a coated implant would be pressed to the bone during implanting, and a wet coating compressed into a few $100 \mu \mathrm{m}$ thin layer, which can fit into the so-called trabecular surface of the implant, it is expected that it would, by mimicking the trabecular bone, promote the formation of an osteogenic differentiating cell matrix and also act as a controllable drug-delivery system, before being resorbed completely in such an in vivo environment.

Supplementary Materials: The following are available online at http://www.mdpi.com/2079-6412/10/5/434/s1: Table S1: surface tension (ST) properties with its polar $\left(\gamma_{1}^{\mathrm{p}}\right)$ and dispersive $\left(\gamma_{1}^{\mathrm{d}}\right)$ components, and contact angles on poly(tetrafluoroethylene) (CAPTFE) of test liquids and GEL solutions; Table S2: measured advancing $\left(\phi_{\mathrm{a}}\right)$ and receding $\left(\phi_{\mathrm{r}}\right)$ contact angles $(\mathrm{CA})$ of test liquids on differently surface-textured Ti-6Al-4V substrates; and Table S3: measured advancing $\left(\phi_{\mathrm{a}}\right)$ and receding $\left(\phi_{\mathrm{r}}\right)$ contact angles $(\mathrm{CA})$ of GEL solutions on differently surface-textured Ti-6Al-4V substrates.

Author Contributions: Formal analysis, Z.P. and T.V.; investigation, S.P.; supervision, I.D. and V.K.; writing-original draft, S.P. and V.K.; and writing—review and editing, V.K. and I.D. All authors have read and agreed to the published version of the manuscript.

Funding: This research was funded by the Erasmus Mundus (Grant No. EMA2-2013-2540/001001-EM-EUPHRATES) and by the Slovenian Research Agency (Project No. J3-9262 and Core Funding No. P2-0157).

Acknowledgments: The authors are highly obligated to Ortotip, LLC Maribor, Slovenia for fabricating the SLM Ti-6Al-4V alloy samples from the provided CAD model.

Conflicts of Interest: The authors declare no conflict of interest. 


\section{References}

1. Benedetti, M.; Torresani, E.; Leoni, M.; Fontanari, V.; Bandini, M.; Pederzolli, C.; Potrich, C. The effect of post-sintering treatments on the fatigue and biological behavior of Ti-6Al-4V ELI parts made by selective laser melting. J. Mech. Behav. Biomed. Mater. 2017, 71, 295-306. [CrossRef] [PubMed]

2. Lek, J.Y.; Bhowmik, A.; Tan, A.W.Y.; Sun, W.; Song, X.; Zhai, W.; Buenconsejo, P.J.; Li, F.; Liu, E.; Lam, Y.M.; et al. Understanding the microstructural evolution of cold sprayed Ti-6Al-4V coatings on Ti-6Al-4V substrates. Appl. Surf. Sci. 2018, 459, 492-504. [CrossRef]

3. Vanderleyden, E.; Van Bael, S.; Chai, Y.C.; Kruth, J.P.; Schrooten, J.; Dubruel, P. Gelatin functionalised porous titanium alloy implants for orthopaedic applications. Mater. Sci. Eng. C 2014, 42, 396-404. [CrossRef] [PubMed]

4. Wang, R.C.C.; Hsieh, M.C.; Yang, S.P.; Chuang, P.K.; Lin, J.C.; Yang, C.Y.; Lee, T.M. Characteristics and cyto-compatibility of collagen/Ca-P coatings on Ti6Al4V substrate. Surf. Coat. Technol. 2011, 205, 4683-4689. [CrossRef]

5. Xiu, P.; Jia, Z.; Lv, J.; Yin, C.; Cai, H.; Song, C.; Leng, H.; Zheng, Y.; Liu, Z.; Cheng, Y. Hierarchical micropore/nanorod apatite hybrids in-situ grown from 3-D Printed macroporous Ti6Al4V implants with improved bioactivity and osseointegration. J. Mater. Sci. Technol. 2017, 33, 179-186. [CrossRef]

6. Wauthle, R.; Van Der Stok, J.; Yavari, S.A.; Van Humbeeck, J.; Kruth, J.P.; Zadpoor, A.A.; Weinans, H.; Mulier, M.; Schrooten, J. Additively manufactured porous tantalum implants. Acta Biomater. 2015, 14, 217-225. [CrossRef]

7. Duan, K.; Wang, R. Surface modifications of bone implants through wet chemistry. J. Mater. Chem. 2006, 16, 2309-2321. [CrossRef]

8. Pylypchuk, I.V.; Gorbyk, P.P.; Petranovska, A.L.; Korduban, O.M.; Markovsky, P.E.; Ivasyshyn, O.M. Chapter 7-Formation of biomimetic hydroxyapatite coatings on the surface of titanium and Ti-containing alloys: Ti-6Al-4V and Ti-Zr-Nb. In Surface Chemistry of Nanobiomaterials, 1st ed.; Grumezescu, A., Ed.; William Andrew Publishing: Norwich, NY, USA, 2016; pp. 193-229. ISBN 978-0-323-42861-3.

9. Vanderleyden, E.; Van Hoorebeke, L.; Schacht, E.; Dubruel, P. Comparative study of collagen and gelatin coatings on titanium surfaces. Macromol. Symp. 2011, 309-310, 190-198. [CrossRef]

10. Kuttappan, S.; Mathew, D.; Nair, M.B. Biomimetic composite scaffolds containing bioceramics and collagen/gelatin for bone tissue engineering - A mini review. Int. J. Biol. Macromol. 2016, 93, 1390-1401. [CrossRef]

11. Nouri, A.; Hodgson, P.D.; Wen, C. Biomimetic porous titanium scaffolds for orthopaedic and dental applications; InTech: Milton, Australia, 2010.

12. Li, J.P.; Li, S.H.; Van Blitterswijk, C.A.; de Groot, K. A novel porous Ti6Al4V: Characterization and cell attachment. J. Biomed. Mater. Res. A 2005, 73, 223-233. [CrossRef]

13. Jiang, T.; Zhang, Z.; Zhou, Y.; Liu, Y.; Wang, Z.; Tong, H.; Shen, X.; Wang, Y. Surface functionalization of titanium with chitosan/gelatin via electrophoretic deposition: Characterization and cell behavior. Biomacromolecules 2010, 11, 1254-1260. [CrossRef] [PubMed]

14. Kiran, A.S.K.; Sampath Kumar, T.S.; Perumal, G.; Sanghavi, R.; Doble, M.; Ramakrishna, S. Dual nanofibrous bioactive coating and antimicrobial surface treatment for infection resistant titanium implants. Prog. Org. Coat. 2018, 121, 112-119. [CrossRef]

15. Gómez, S.; Vlad, M.D.; López, J.; Fernández, E. Design and properties of 3D scaffolds for bone tissue engineering. Acta Biomater. 2016, 42, 341-350. [CrossRef]

16. Karageorgiou, V.; Kaplan, D. Porosity of 3D biomaterial scaffolds and osteogenesis. Biomaterials 2005, 26, 5474-5491. [CrossRef] [PubMed]

17. Wang, Z.; Wang, C.; Li, C.; Qin, Y.; Zhong, L.; Chen, B.; Li, Z.; Liu, H.; Chang, F.; Wang, J. Analysis of factors influencing bone ingrowth into three-dimensional printed porous metal scaffolds: A review. J. Alloys Compd. 2017, 717, 271-285. [CrossRef]

18. Van Cleynenbreugel, T.; Schrooten, J.; Van Oosterwyck, H.; Vander Sloten, J. Micro-CT-based screening of biomechanical and structural properties of bone tissue engineering scaffolds. Med. Biol. Eng. Comput. 2006, 44, 517-525. [CrossRef] 
19. Vehof, J.W.M.; Fisher, J.P.; Dean, D.; van der Waerden, J.P.C.M.; Spauwen, P.H.M.; Mikos, A.G.; Jansen, J.A. Bone formation in transforming growth factor beta-1-coated porous poly(propylene fumarate) scaffolds. J. Biomed. Mater. Res. 2002, 60, 241-251. [CrossRef]

20. Taniguchi, N.; Fujibayashi, S.; Takemoto, M.; Sasaki, K.; Otsuki, B.; Nakamura, T.; Matsushita, T.; Kokubo, T.; Matsuda, S. Effect of pore size on bone ingrowth into porous titanium implants fabricated by additive manufacturing: An in vivo experiment. Mater. Sci. Eng. C 2016, 59, 690-701. [CrossRef]

21. Esen, Z.; Bor, Ş. Processing of titanium foams using magnesium spacer particles. Scr. Mater. 2007, 56, 341-344. [CrossRef]

22. Bram, M.; Schiefer, H.; Bogdanski, D.; Köller, M.; Buchkremer, H.P.; Stöver, D. Implant surgery: How bone bonds to PM titanium. Met. Powder Rep. 2006, 61, 26-31. [CrossRef]

23. Fukushima, M.; Ohji, T.; Hyuga, H.; Matsunaga, C.; Yoshizawa, Y.I. Effect of gelatin gel strength on microstructures and mechanical properties of cellular ceramics created by gelation freezing route. J. Mater. Res. 2017, 32, 3286-3293. [CrossRef]

24. Gorgieva, S.; Kokol, V. Processing of gelatin-based cryogels with improved thermomechanical resistance, pore size gradient, and high potential for sustainable protein drug release. J. Biomed. Mater. Res. A 2015, 103, 1119-1130. [CrossRef] [PubMed]

25. Kim, B.; Gil, H.B.; Min, S.G.; Lee, S.K.; Choi, M.J. Effects of pressure-shift freezing on the structural and physical properties of gelatin hydrogel matrices. Korean J. Food Sci. Anim. Resour. 2014, 34, 33-39. [CrossRef]

26. Fayyazbakhsh, F.; Solati-Hashjin, M.; Keshtkar, A.; Shokrgozar, M.A.; Dehghan, M.M.; Larijani, B. Novel layered double hydroxides-hydroxyapatite/gelatin bone tissue engineering scaffolds: Fabrication, characterization, and in vivo study. Mater. Sci. Eng. C 2017, 76, 701-714. [CrossRef]

27. Huang, Z.M.; Qi, Y.Y.; Du, S.H.; Feng, G.; Unuma, H.; Yan, W.Q. Promotion of osteogenic differentiation of stem cells and increase of bone-bonding ability in vivo using urease-treated titanium coated with calcium phosphate and gelatin. Sci. Technol. Adv. Mater. 2013, 14, 55001. [CrossRef] [PubMed]

28. Rohanizadeh, R.; Swain, M.V.; Mason, R.S. Gelatin sponges (Gelfoam®) as a scaffold for osteoblasts. J. Mater. Sci. Mater. Med. 2008, 19, 1173-1182. [CrossRef]

29. Ulubayram, K.; Nur Cakar, A.; Korkusuz, P.; Ertan, C.; Hasirci, N. EGF containing gelatin-based wound dressings. Biomaterials 2001, 22, 1345-1356. [CrossRef]

30. Goodman, S.; Toksvig-Larsen, S.; Aspenberg, P. Ingrowth of bone into pores in titanium chambers implanted in rabbits: Effect of pore cross-sectional shape in the presence of dynamic shear. J. Biomed. Mater. Res. 1993, 27, 247-253. [CrossRef]

31. Pal, S.; Gubeljak, N.; Hudak, R.; Lojen, G.; Rajtukova, V.; Predan, J.; Kokol, V.; Drstvensek, I. Tensile properties of selective laser melting products affected by building orientation and energy density. Mater. Sci. Eng. A 2018, 743, 637-647. [CrossRef]

32. Rulison, C. Two-component surface energy characterization as a predictor of wettability and dispersability. Krus. Appl. note AN213 2000, 1-22.

33. Zandi, M. Studies on the Gelation of Gelatin Solutions and on the Use of Resulting Gels for Medical Scaffolds. Ph.D. Thesis, University of Duisburg-Essen, Duisburg, Germany, February 2008.

34. Gornall, J.L.; Terentjev, E.M. Universal kinetics of helix-coil transition in gelatin. Phys. Rev. E: Stat. Nonlinear Soft Matter Phys. 2008, 77, 031908. [CrossRef] [PubMed]

35. Lan Levengood, S.K.; Polak, S.J.; Poellmann, M.J.; Hoelzle, D.J.; Maki, A.J.; Clark, S.G.; Wheeler, M.B.; Wagoner Johnson, A.J. The effect of BMP-2 on micro- and macroscale osteointegration of biphasic calcium phosphate scaffolds with multiscale porosity. Acta Biomater. 2010, 6, 3283-3291. [CrossRef] [PubMed]

36. Mantila Roosa, S.M.; Kemppainen, J.M.; Moffitt, E.N.; Krebsbach, P.H.; Hollister, S.J. The pore size of polycaprolactone scaffolds has limited influence on bone regeneration in an in vivo model. J. Biomed. Mater. Res. - Part A 2010, 92, 359-368. [CrossRef] [PubMed]

37. Itala, A.I.; Ylanen, H.O.; Ekholm, C.; Karlsson, K.H.; Aro, H.T. Pore diameter of more than $100 \mu \mathrm{m}$ is not requisite for bone ingrowth in rabbits. J. Biomed. Mater. Res. 2001, 58, 679-683. [CrossRef] [PubMed]

38. Kuboki, Y.; Jin, Q.; Takita, H. Geometry of carriers controlling phenotypic expression in BMP-induced osteogenesis and chondrogenesis. J. Bone Joint Surg. Am. 2001, 83, S105-S115. [CrossRef] [PubMed]

39. Chibowski, E.; Terpilowski, K. Comparison of apparent surface free energy of some solids determined by different approaches. In Contact Angle, Wettability and Adhesion, Volume 6, 1st ed.; Mittal, K.L., Ed.; CRC Press: Boca Raton, FL, USA, 2009; pp. 281-310. 
40. Cicciu, M.; Fiorillo, L.; Herford, A.S.; Crimi, S.; Bianchi, A.; D’Amico, C.; Laino, L.; Cervino, G. Bioactive titanium surfaces: Interactions of eukaryotic and prokaryotic cells of nano devices applied to dental practice. Biomedicines 2019, 7, 12. [CrossRef]

41. Knorr, S.D.; Combe, E.C.; Wolff, L.F.; Hodges, J.S. The surface free energy of dental gold-based materials. Dent. Mater. 2005, 21, 272-277. [CrossRef]

42. Sun, C.C.; Lee, S.C.; Hwang, W.C.; Hwang, J.S.; Tang, I.T.; Fu, Y.S. Surface free energy of alloy nitride coatings deposited using closed field unbalanced magnetron sputter ion plating. Mater. Trans. 2006, 47, 2533-2539. [CrossRef]

43. Peršin, Z.; Stenius, P.; Stana-Kleinschek, K. Estimation of the surface energy of chemically and oxygen plasma-treated regenerated cellulosic fabrics using various calculation models. Text. Res. J. 2011, 81, 1673-1685. [CrossRef]

44. Schuster, J.M.; Schvezov, C.E.; Rosenberger, M.R. Analysis of the results of surface free energy measurement of Ti6Al4V by different methods. Procedia Mater. Sci. 2015, 8, 732-741. [CrossRef]

45. Fowkes, F.M. Donor-acceptor interactions at interfaces. J. Adhes. 1972, 4, 155-159. [CrossRef]

46. Van Oss, C.J.; Chaudhury, M.K.; Good, R.J. Interfacial Lifshitz-van der Waals and polar interactions in macroscopic systems. Chem. Rev. 1988, 88, 927-941. [CrossRef]

47. Owens, D.K.; Wendt, R.C. Estimation of the surface free energy of polymers. J. Appl. Polym. Sci. 1969, 13, 1741-1747. [CrossRef]

48. Hallab, N.J.; Bundy, K.J.; O'Connor, K.; Moses, R.L.; Jacobs, J.J. Evaluation of metallic and polymeric biomaterial surface energy and surface roughness characteristics for directed cell adhesion. Tissue Eng. 2001, 7, 55-71. [CrossRef]

49. Hallab, N.J.; Bundy, K.J.; O'Connor, K.; Clark, R.; Moses, R.L. Cell adhesion to biomaterials: Correlations between surface charge, surface roughness, adsorbed protein, and cell morphology. J. Long-Term Eff. Med. Implant. 1995, 5, 209-231. [CrossRef]

50. Ceotto, D. Empirical relation between surface tension and density for some pure liquid metals. Russ. J. Phys. Chem. A 2015, 89, 2327-2330. [CrossRef]

51. Eng, C.; Osgouei, A.; Abbas, G. Density and temperature dependencies of liquid surface tension. Iran J. Chem. Chem. Eng. (IJCCE) 2011, 30, 79-90.

52. Osorio, F.A.; Bilbao, E.; Bustos, R.; Alvarez, F. Effects of concentration, bloom degree, and pH on gelatin melting and gelling temperatures using small amplitude oscillatory rheology. Int. J. Food Prop. 2007, 10, 841-851. [CrossRef]

53. Cox, R.A. Acids and Bases. Solvent effects on acid-base strength. By Brian G. Cox. Angew. Chem. Int. Ed. 2013, 52, 7638. [CrossRef]

54. Wang, J.; De Boer, J.; De Groot, K. Preparation and characterization of electrodeposited calcium phosphate/chitosan coating on Ti6Al4V plates. J. Dent. Res. 2004, 83, 296-310. [CrossRef]

55. Ramay, H.R.R.; Zhang, M. Biphasic calcium phosphate nanocomposite porous scaffolds for load-bearing bone tissue engineering. Biomaterials 2004, 25, 5171-5180. [CrossRef] [PubMed]

(C) 2020 by the authors. Licensee MDPI, Basel, Switzerland. This article is an open access article distributed under the terms and conditions of the Creative Commons Attribution (CC BY) license (http://creativecommons.org/licenses/by/4.0/). 